\title{
On the Biology of Sagitta. IV. Observations on the Natural History of Sagitta elegans Verrill and Sagitta setosa J. Müller in the Plymouth Area.
}

By

\author{
F. S. Russell, D.S.C., B.A., \\ Naturalist at the Plymouth Laboratory.
}

With 3 Figures in the Text.

VERY little is known of the habits and life-cycles of any of our plankton animals throughout the year. In this report an attempt is made to piece together the results of studies of different aspects of the natural history of Sagitta elegans Verrill and Sagitta setosa J. Müller in the offshore waters near Plymouth, to see how far we can get towards making a complete picture of the two species.

I have already published three reports attempting to give an idea of the growth and breeding of Sagitta throughout the year $(\mathbf{9}, \mathbf{1 0}$, and 11), and an account of its changes in vertical distribution from day to night (8). In the present paper I shall give results of observations on the vertical distribution of the two species in the daytime, together with data on their relative abundance during the seasons, and review these results and those on breeding and growth as a whole. The paper is accordingly divided into three parts : 1 , on the vertical distribution ; 2 , on the seasonal abundance ; and 3 , the whole picture as far as indications show at the moment.

\section{The Vertical Distribution of S. elegans and S. setosa.}

Collections were made in 1926, during the period from April to September inclusive, with the 2-metre stramin ring-trawl. Some of the results of these collections have already been published, namely, on the young fishes ( $\mathbf{7}$ ) and on the copepod, Calanus finmarchicus (6). The full details of collecting have been given in the first of these publications ( $\boldsymbol{y})$, so that it will be sufficient here to give only the actual results of the collections. These are shown in Table I and in the diagrams of the vertical distribution in Figure 1. In this figure are given the percentage vertical distribution in the daytime at different times of the year for S. elegans (above) and S. setosa (below). The actual distributions on the days in question can be seen at a glance from the figure. It is, however, necessary 


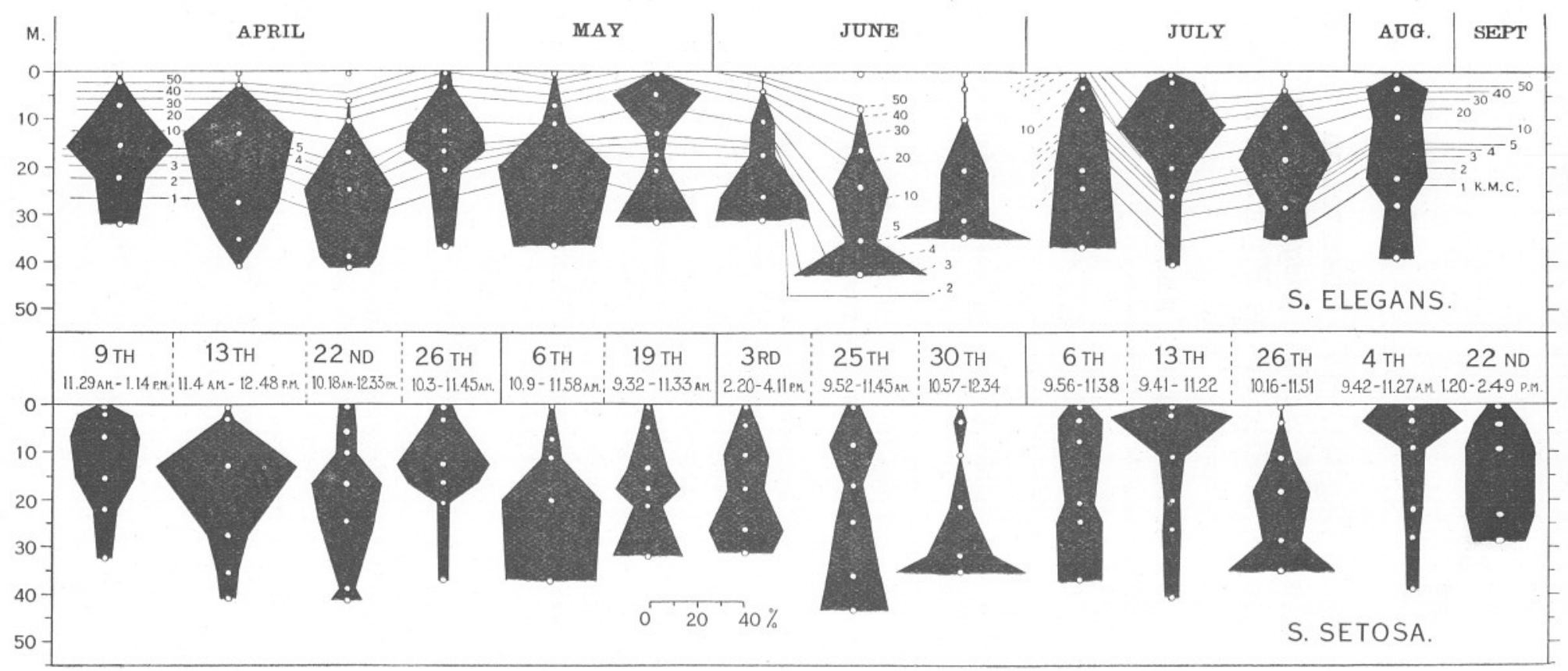

FIG. 1.-The percentage vertical distribution of Sagilla elegans and of S. selosa in the daytime on the dates given in 1926 . The white spots and black circles indicate the average depths at which the hauls were made. The times given are Greenwich Mean Time and denote the time at which the first haul in a series was begun and at which the last haul was finished. In the upper half are superimposed the curves of equal light intensities in kilo metre-candles based on transparency measurements with the Secchi disc at the time of collecting and estimated air illuminations (see text). On June 30th there was no transparency measurement. 
to point out that this distribution relates only to a population such as is sampled by the stramin material of which the ring-trawl is made. On the whole, therefore, the majority of the early stages, probably from about 7 or $8 \mathrm{~mm}$. in length and less, will be missing.* It must also be realised that these diagrams show the distributions of the populations thus sampled as a whole; it has already been shown by others and myself (8) that there is a tendency for the younger animals to be nearer the surface than the older. It is probable though that on account of the selective capacity of the stramin net our data deal mostly with the larger individuals so that we have a fairly true idea of the behaviour of the average-sized fullgrown individuals; the very small and very large will also usually be too few in number to make any very marked difference in the precentage figures.

At the time the collections were taken observations were made on the weather and sky conditions, and also on the transparency of the water by means of a Secchi disc. These observations are published in the complete log given on pages 668 to 670 of a previous report ( $(\boldsymbol{y})$. An attempt has here been made to translate these observations into the rather more definite terms of light intensity. For the past two years Dr. W. R. G. Atkins has kept a continuous light intensity recorder in action with the recording photo-electric cell on the roof of the Plymouth laboratory (3). From studying the curves of intensity thus obtained he has gained a fund of knowledge on the strengths of light to be found at different times of the year under varying weather and sky conditions. On the basis of my observations at the time of collecting he has very kindly given me the approximate light intensities to be expected under the various weather and sky conditions. As each series of collections took about two hours it is necessary to decide on a time on which to base the light intensity approximations, and the times taken are those about midway through the collecting periods.

I give on page 562 the figures for light intensity† given me by Dr. Atkins, the times on which they were based, and also the depths at which the Secchi disc disappeared on the days in question.

From the readings obtained by means of the Secchi disc I have calculated coefficients of absorption for the days in question using the formula $\mu=\frac{1 \cdot 7}{\mathrm{D}}$. given by Poole and Atkins (2, p. 310). It must be realised that this formula is approximate only, being the average of a number of rather widely varying readings as Poole and Atkins' table shows (2, p. 310).

Using the coefficients of absorption thus obtained and allowing for a

* I have confirmed that this is so by comparison with silk net catches at about the same time.

$\dagger$ Based on carbon arc carbonisation. 
reflection loss of $15 \%$ (Poole and Atkins, 2, p. 309), I have calculated what the light intensity might have been beneath the sea's surface using the figures for air illumination given below. From these results I have inserted in Figure 1, on the diagrams for $S$. elegans, the lines of equal intensities for 50, 40, 30, 20, 10, 5, 4, 3, 2, and 1 k.m.c. (On June 30th and Sept. 22nd no Sechi disc observations were made and therefore no intensities could be calculated.)

It cannot be too strongly insisted that these light intensity figures are not actual data obtained at the times of collecting, and that while the

\begin{tabular}{|c|c|c|c|}
\hline 1926. & Time. & k.m.c.* & $\begin{array}{l}\text { S.D. } \\
\text { metres. }\end{array}$ \\
\hline April 9th & 12 p.m. & 85 & $10-12$ \\
\hline 13 th & 11.40 a.m. & 85 & $10-12$ \\
\hline,,$\quad 22 \mathrm{nd}$ & 11 a.m. & 115 & $10-11$ \\
\hline ,, 26th & 10.45 a.m. & 50 & $11 \cdot 5-13$ \\
\hline May 6th & 10.45 a.m. & 82 & $9 \cdot 5-9$ \\
\hline, 19th & 10.15 a.m. & 40 & $11-13$ \\
\hline June 3rd & 3 p.m. & 70 & 10 \\
\hline, , 25th & 10.30 a.m. & 100 & $19 \cdot 5-20 \cdot 5$ \\
\hline ,, 30th & 11.30 a.m. & 115 & - \\
\hline July 6 th & 10.30 a.m. & 26 & 14 \\
\hline, 13th & 10.30 a.m. & 122 & 13 \\
\hline, 26 th & 10.50 a.m. & 115 & 12 \\
\hline Aug. 4th & 10.20 a.m. & 106 & 9 \\
\hline Sept. 22nd & 2 p.m. & 50 & - \\
\hline
\end{tabular}

surface illuminations may reasonably be supposed to lie fairly near the truth the coefficients of absorption as given by the Secchi disc are only very approximate, the effect of a slight increase or decrease in transparency having a comparatively greater effect on the penetration of light than wide variations in surface illumination. I have, however, inserted these calculated results as they probably give a more concrete guide to the light conditions beneath the sea on the days on which collections were made than would such expressions as " cloudless " or "dull."

With this understanding, then, we can examine the diagrams in Figure 1. We notice that from April to June there is a distinct tendency for the Sagitta elegans to move deeper in the water; that while in April they are mostly concentrated around about 15-25 metres, in June they are mostly well below the 20 -metre level, and indeed judging from the low numbers caught (see Table I) it seems probable that the majority may have been lying considerably deeper than the lowest level sampled. At the 
same time there are differences to be noticed from day to day, slight rises or falls in the depths at which the animals are most abundant. It is interesting to note that these differences appear to be definitely correlated with the strength of the light, rising and falling in agreement with the lines of equal intensities.

Bearing in mind the limitations of our method also it is interesting to see that during this period the Sagitta have certainly avoided the highlight intensities from about 20 k.m.c. upwards. There is also an indication that in May and June the regions of maximum abundance lie even below $5 \mathrm{k} . \mathrm{m} . c$. , this perhaps being an indication that with advancing age the Sagitta become more sensitive to light. The only exception to this is on May 19th when a small secondary region of maximum abundance appears at 5 metres; examination of the Sagitta has, however, shown that this maximum was composed entirely of very small individuals and all the larger animals were deep down; the numbers caught on this day also were extremely low.

When now we examine the diagrams for July, August, and September the indications are quite materially different. We find on the three bright days, July 13th and 26th and August 4th, a great number of Sagitta up above the ten-metre level where they must have experienced light intensities of over 20 k.m.c., many living in 30, 40, and even 50 k.m.c.* These are intensities which the Sagitta very definitely seemed to avoid earlier in the year. It is also interesting to note that on July 6th, when the weather was very dull and cloudy and these high-light intensities were not even to be found on the surface itself, the Sagitta were much more evenly distributed from the upper layers downwards, and showed no definite massing at any depth as they did on other days. They were, however, absent at the surface itself.

An examination of the diagrams for $S$. setosa shows exactly the same type of results. In this species, however, the animals are almost consistently a little higher in the water than $S$. elegans. In a previous report on the distribution of $S$. setosa at dusk (8, p. 396) it was stated that " on the whole there is a tendency for all stages to be slightly higher in the water than the corresponding stages of $S$. elegans at the same time: whether this difference is shown also in the daytime we cannot say until further observations have been made." This suggestion then would appear now to be confirmed.

We notice also the same rising towards the surface in July and August, and the tendency towards an even distribution from the surface downwards on July 6th, and also on September 22nd, another dull day, but on this day hardly any S. elegans were caught. It seems almost as though at

* This does not hold so well on July 26th, but the conditions may not have been correctly estimated.

NEW SERIES.-VOL. XVIII. NO. 2. JANUARY, 1933. 
this time of year the lower limit of light intensity above which the Sagitta are perhaps stimulated to move upwards towards an optimum is very high, and that below this limit they become indifferent to light, a phenomenon that would only have appeared after dusk intensities earlier in the year. It is interesting that the copepod Anomalocera patersoni shows a parallel behaviour. This is an animal which on bright sunny days crowds right near the surface, and it also shows a tendency to become more evenly distributed from the surface downwards on dull days (see 4, p. 585 and Fig. 7). One wonders whether after such dull days Sagitta would migrate at all at night.

If we compare the results for Sagitta given in Figure 1 with those in a previous publication (4, p. 577 and Fig. 5) recording similar observations made in 1925 we find a general confirmation. On that occasion the correct identification of the Sagitta had not been made and the two species were grouped together as $S$. bipunctata. The diagrams given in Figure 5 of 4 appear, however, to be so like those for S. elegans in 1926 given in Figure 1 here that it is probable that they refer to this species. The 1925 results also show the sudden rise of Sagitta into the upper layers during July and August, and the avoidance of the actual surface itself which is more characteristic of $S$. elegans than of $S$. setosa.

This appearance of Sagitta in the upper well-illuminated layers in July and August, and perhaps September, is very striking. I have already shown that the copepod Calanus finmarchicus shows the same behaviour (6). A similar change in vertical distribution was also shown by Tomopteris helgolandica in 1925 (4, p. 578; Fig. 5, and pp. 575-576) although they did not seem to rise so near the surface. The post-larval young of teleostean fish also showed a similar type of change, the young of summer spawning species tending on the whole to live nearer the surface than those of spring spawning species ( $\boldsymbol{\%}$, p. 646).

That animals belonging to such widely different groups should all show this same type of change in behaviour at this period of the year is very remarkable and it must surely indicate a phenomenon of rather fundamental importance, and may have some significance in the relation of vitamin content (12).

\section{The Seasonal Abundance of S. elegans and S. setosa.}

Since February, 1930, regular collections, usually at weekly intervals, have been made with the 2 -metre stramin ring-trawl at a position 2 miles east of the Eddystone. These were oblique hauls of half an hour's duration (see $\%$, p. 640). The numbers of $S$. elegans and S. setosa in these catches have been recorded and for most dates are already published in Tables in $\mathbf{9}, \mathbf{1 0}$, and 11 . The results of any collections not yet published are given in Table II at the end of this paper. The numbers of Sagitta caught in 
each haul during the period February, 1930, to September, 1932, are shown graphically in Figure 2 in which the curve for $S$. elegans is the unbroken line and that for $S$. setosa is the broken line. In the lower half of this same figure (Fig. 2) are given the percentage proportions of the two species in each catch (S. elegans, black; S. setosa, white). It can be seen at once from these percentage figures that during the period examined there has been a change over in the composition of the catches from almost pure S. elegans in 1930 to almost pure S. setosa in 1932. A similar preponderance of one species over the other in different years has also been shown by Meek (1) for the North Sea.

As regards the actual abundance there appears to be a regular periodicity in the curves. That for S. elegans shows two periods of maximum abundance both in 1930 and in 1931, namely, in February and in July, August and September in 1930, and in March and in August-September in 1931. After this date its numbers died down too low to show significant changes, though they are slightly indicated in January and in August in 1932.

The curve for $S$. setosa also appears to show two periods of maximum abundance both in 1931 and in 1932, namely April and a period starting in August and lasting until November in 1931, and in March and in August to November again in 1932 (see Table II, p. 573). In 1930 S. setosa was not sufficiently abundant to give significant results.

With our knowledge of the breeding periods of Sagitta one would assume that the increase in numbers shown by both species in these oblique haul collections was due to an increase in stock following the successive summer spawnings. This stock of $S$. elegans appears to die down in September after the last spawning for the year, while the stock of S. setosa appears to die down in November after the last spawning of the year, which for this species occurs in October. During the winter months their numbers are very low. From further observations it appears, however, that this impression may be false. From July, 1927, until May, 1928 , collections were made with a stramin plankton net fishing immediately above the bottom ( 5 and $\boldsymbol{7}$, p. 647 ). These collections were made at three positions offshore, usually at weekly intervals, and each haul was of half an hour's duration. The numbers of Sagitta taken in these collections are given in Table III, in which also are given the average catch per week and these averages multiplied by $8.5(7$, p. 647) to make them comparable with those of a two-metre stramin net.

Examination of Table III shows that there is no indication whatever of the great diminution of numbers of Sagitta shown by the oblique hauls in the winter months in Figure 2.

It is unfortunate that oblique haul collections are not available for the same twelve months as those in which the bottom-net catches were made. 


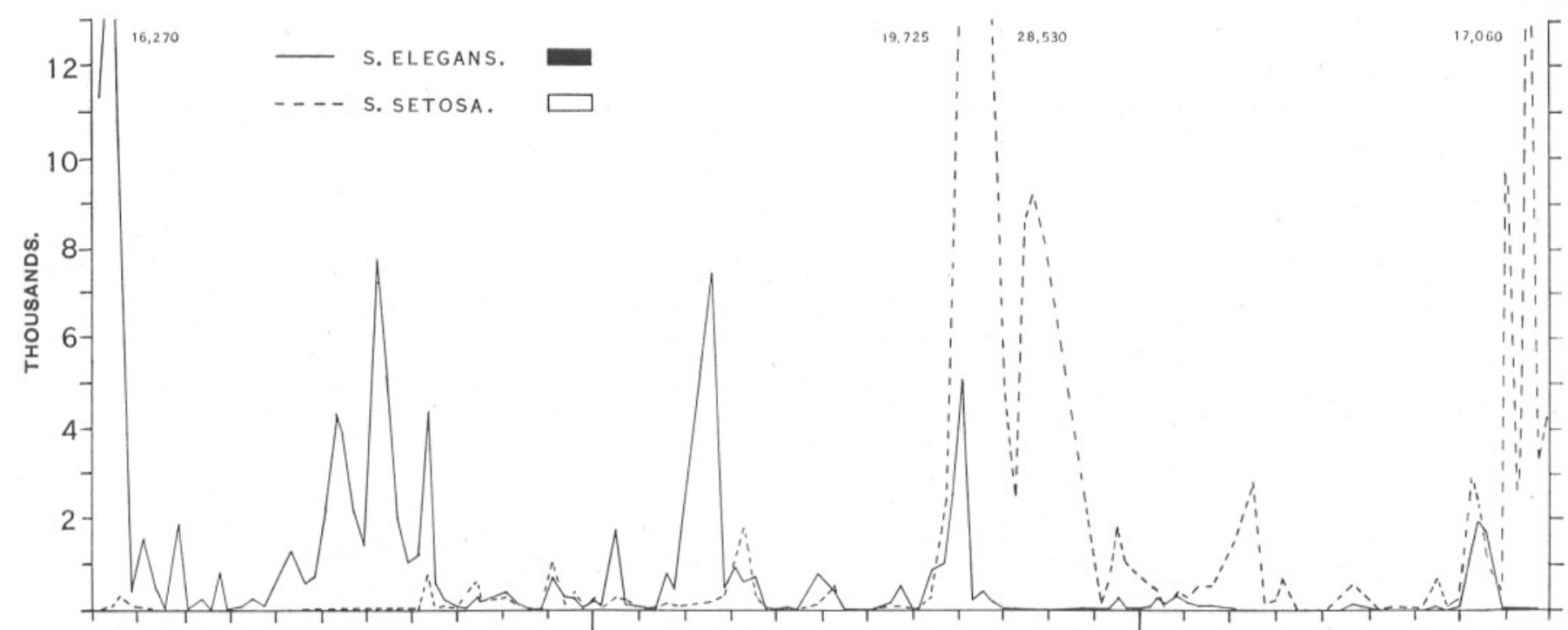

fEb MAR apL MAY JUN JUL AUG SEP OCt NOY DEC JAN FEB MAR APL MAY JUN JUL AUG SEP OCt NOY DEC JAN FEB MAR APL MAY JUN JUL AUG SEP

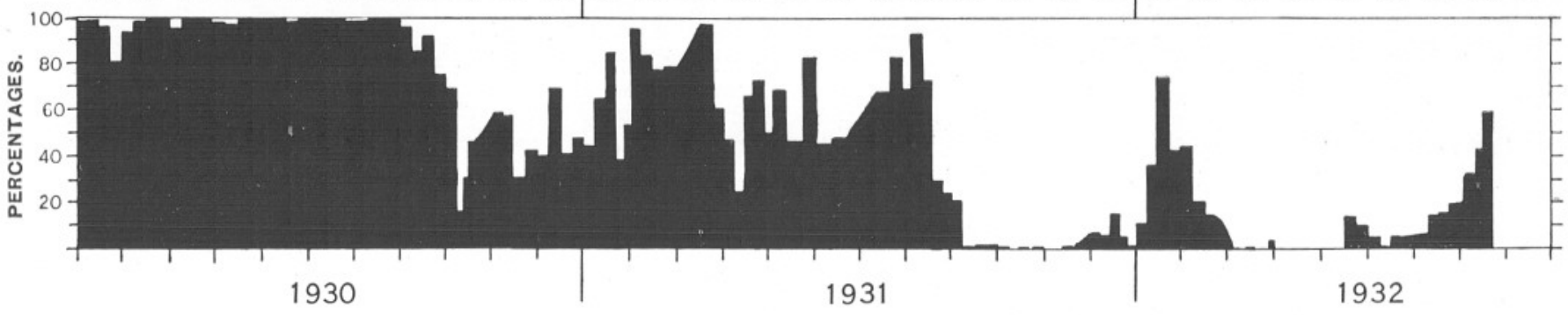

Fig. 2.-Above, curves showing the actual abundance of S. elegans (_- ) and S. setosa (--- - ) in half-hour oblique hauls with the 2-metre ring-trawl made usually at weekly intervals during the years 1930, 1931, and 1932. (The numbers are in thousands.) Below, the percentage composition of the Sagitta populations during the same period; $S$. elegans, black; $S$. setosa, white.

N.B. As shown in the text on page 565 the picture of actual seasonal abundance produced by the upper curves may be fallacious, in that at certain periods of the year the Sagitta may be below the lowest layer sampled by the net. 
But in view of the consistency of the results shown by the oblique hauls it seems permissible to assume that in the twelve months in 1927-1928 if oblique hauls had been available the same dying down in numbers would have been shown during the winter months as in other years. This would indicate that the decrease in numbers does not represent an actual dying off of the Sagitta, but is due to a descent of the animals to the bottom layers, either very close to the bottom itself or at any rate below the deepest level reached by the oblique hauls. I have indirect confirmatory evidence that this may be so in that in the bottom-net catches the copepod, Calanus finmarchicus, did show a genuine diminution in numbers in the winter months as it does in the oblique hauls. If Sagitta too dies down it should also have shown a diminution in the bottom catches as did Calanus, but as we have said this was not so.

There is furthermore evidence that most small catches of Sagitta occurred in the bottom net during the months May to October ; and it is significant that in July, August, and September, at any rate, the Sagitta are high in the water. Possibly also S. setosa may be high in the water in October as it is spawning during that month-the bottom-net catches for October were almost all $S$. setosa, showing that it predominated over $S$. elegans at that period. One cannot help feeling that simultaneous oblique and bottom hauls would show that generally when the numbers of Sagitta were low in one net they would be high in the other and vice versa. There is, however, a possibility that there may be a genuine diminution in numbers in May and June as both the oblique hauls and the bottom hauls show low numbers in these months; but the number of observations made with the bottom net in these months is insufficient to draw definite conclusions, and I have already shown that on a very bright day in June the Sagitta may be driven right to the bottom and only appear in larger numbers in hauls in the upper water layers at night (8, p. 404). In the daytime the oblique hauls would fish for the majority of the time in the upper unpopulated layers and would consequently give small catches.

A complete analysis of the two species in the bottom-net catches was not made as the results would not have warranted the labour, seeing that oblique haul catches were not available at the same time. But an examination of occasional catches showed that while in the period June, 1927, to February, 1928, S. setosa predominated completely, after that date $S$. elegans and $S$. setosa were present in about equal proportions.

The results so far obtained emphasize that in a study of the seasonal distribution of Sagitta it is essential that all water layers be sampled from the very bottom to the surface if we are not to be misled in our conclusions. I have already shown this to be so for adult Tomopteris helgolandica (4, p. 576). 


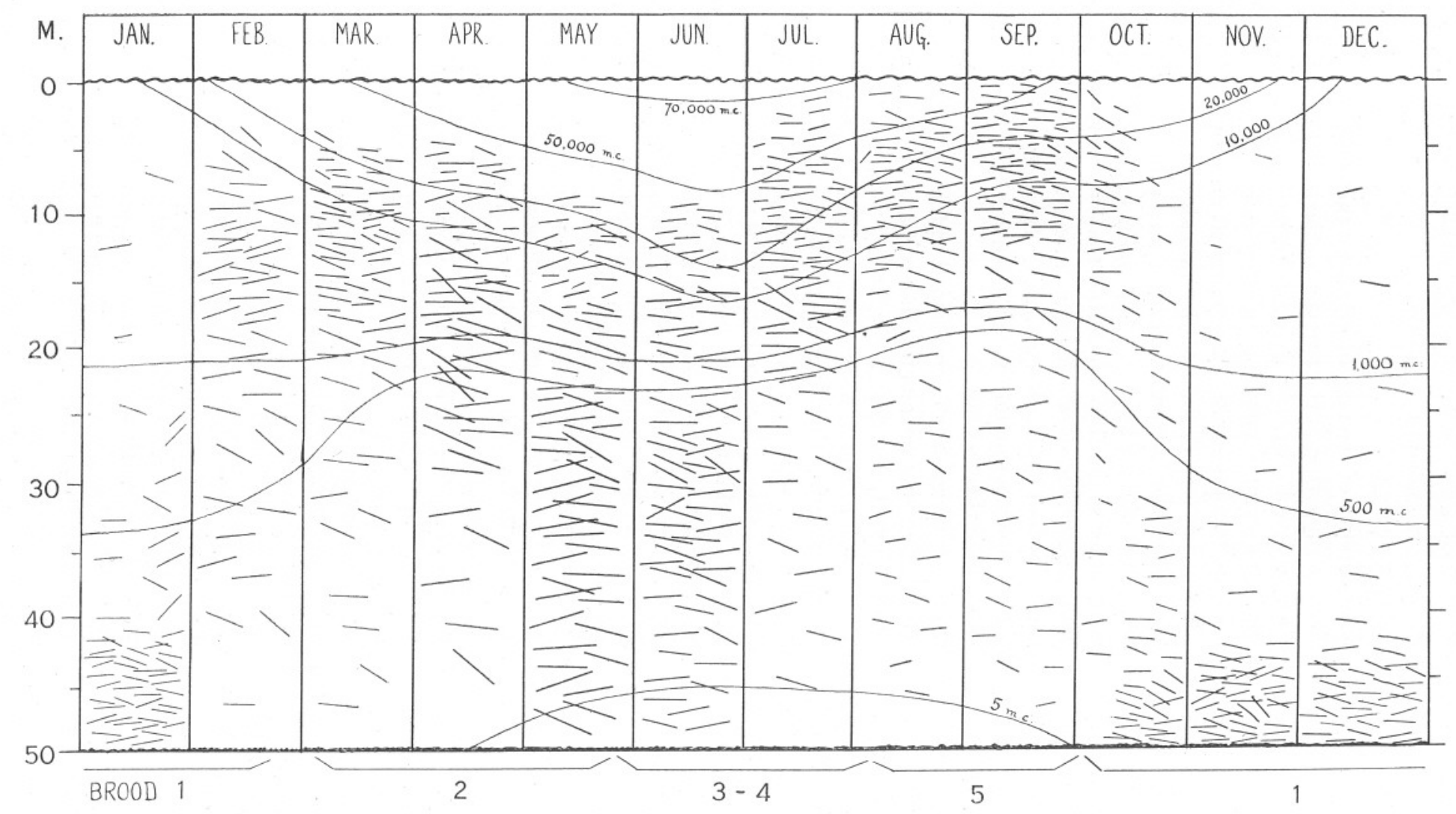

Fig. 3.-Hypothetical picture of vertical distribution of $S$. elegans throughout the year at midday on a bright day. The Sagitta are drawn to scale (half natural) to indicate the successive changes in the sizes of the adults of the different broods. Curves of equal intensities of light in metre candles that might be expected at midday on cloudless days at different times of the year are inserted based on the work of Atkins and Poole ( 2 ). 


\section{The Natural History of Sagitta in Offshore Waters off Plymouth.}

When we review the results of the previous observations on Sagitta we feel that we can begin to assemble a partial picture of their life-stories and habits.

Sagitta is an animal which passes through several generations in the year, possibly 5 or 6 according to the species. During November to January there is no breeding. The adults of the different broods grow to different sizes, the adults appearing in April and May being the largest on the average. During the spring months the Sagitta are living in the upper water layers in the daytime, appearing to dwell around a depth at which a light intensity of a little below 20 k.m.c. will be found. At the same time the larger individuals tend to seek lower intensities and thus go deeper in the water which is consonant with the increased sensitivity with advancing age. At this period of the year (April and May) on dull days the Sagitta will be nearer the surface than on fine days. The brood succeeding in June appears to show a similar habit and on very bright days may retire almost to the bottomitself. But the new broods appearing in July and August show a marked difference, not avoiding on bright days those depths in the upper water layers where intensities of 20 k.m.c. and over may be found. At this time of year if the day is dull they appear to be indifferent to the light and may be found in equal numbers at almost any depth. The offispring of the last spawning brood in September in S. elegans and October in $S$. setosa perhaps (if the bottom net results be rightly construed) leave the upper layers and keep near the bottom until the following February, when they are mature and ready to spawn, at which time they appear to rise in the water again, as is indicated by the sudden increase in numbers of $S$. elegans in the oblique hauls in February. Throughout the year, at any rate in the summer months, the vertical distribution of Sagitta changes daily when night comes on, the animals either migrating right to the surface at dusk or exhibiting other types of distribution ending in an even distribution at night according to their position in the water on the previous day.

This is the general indication that appears to come out of these researches and I have expressed this idea graphically in Figure 3 for S. elegans. In this figure the Sagitta are drawn to scale (half natural size) to show the difference in size of the adults at different times of the year. I have also inserted the curves of equal intensities of light that might be expected about midday on cloudless days (based on Poole and Atkins, 2). Of special interest is the brightening of the deeper layers in the winter owing to the increasing transparency of the water perhaps due to the scarcity of plankton animals at that time. (For an idea of the approximate strengths of light see 8, p. 400 and Fig. 5.) It must be realised 
that this figure is very hypothetical as it cannot be said yet that any of our results are sufficiently definite to supply the whole picture, especially during the period November to March inclusive; but I have given it in this form to clarify our ideas on the subject so that we may see the whole problem at a glance, and in order that others may be stimulated to make a completer survey of this and viher plankton animals.

\section{SUMMARY.}

1. Observations are given on the vertical distribution of Sagitta elegans and $S$. setosa in the daytime.

2. An account is given of the seasonal abundance of both species of Sagitta throughout the year as shown by collections made with oblique hauls with the 2-metre stramin ring-trawl and hauls with a bottom plankton net.

3. An attempt is made to piece together as much as possible of the life-stories and habits of Sagitta in offshore waters off Plymouth on the basis of these and previous observations.

\section{REFERENCES.}

1. Meek, Alexander. On Sagitta elegans and Sagitta setosa from the Northumbrian Plankton, with a Note on a Trematode Parasite. Proc. Zool. Soc. London, 1928, No. 29, pp. 743-776.

2. Poole, H. H., and Atrins, W. R. G. Photo-electric Measurements of Submarine Illumination throughout the Year. Journ. Mar. Biol. Assoc., N.S., Vol. XVI, No. 1, p. 297, 1929.

3. Atkins, W. R. G., and Poole, H. H. The Photo-electric Recording of Daylight. Nature, No. 3148, Vol. 125, p. 305, 1930.

4. Russelt, F. S. The Vertical Distribution of Marine Macroplankton. V. The Distribution of Animals caught in the Ring-trawl in the Daytime in the Plymouth Area. Journ. Mar. Biol. Assoc., N.S., Vol. XIV, No. 3, pp. 557-608, 1927.

5. — - A net for catching Plankton near the bottom. Ibid., Vol. XV, No. 1, pp. 105-108, 1928.

6. _ The Vertical Distribution of Marine Macroplankton. VII. Observations on the Behaviour of Calanus finmarchicus. Ibid. Vol. XV, No. 2, pp. 429-454, 1928.

7. The Vertical Distribution of Marine Macroplankton. IX. The Distribution of the Pelagic Young of Teleostean Fishes in the Daytime in the Plymouth Area. Ibid. Vol. XVI, No. 2, pp. 639-676, 1930. 
8. Russell, F. S. The Vertical Distribution of Marine Macroplankton. X. Notes on the Behaviour of Sagitta in the Plymouth Area. Ibid. Vol. XVII, No. 2, p. 391, 1931.

9. — On the Biology of Sagitta. The Breeding and Growth of Sagitta elegans Verrill in the Plymouth Area, 1930-31. Ibid. Vol. XVIII, No. 1, pp. 131-146, 1932.

10. — On the Biology of Sagitta. II. The Breeding and Growth of Sagitta setosa J. Müller in the Plymouth Area, 1930-31, with a comparison with that of $S$. elegans Verrill. Ibid. Vol. XVIII, No. 1, pp. 147-160, 1932.

11. On the Biology of Sagitta. III. A Further Observation on the Growth and Breeding of Sagitta setosa in the Plymouth Area. Ibid. Vol. XVIII, No. 2, pp. 555-558, 1933.

12. - Vitamin Content of Marine Plankton. Nature, Sept. 27th, 1930, p. 472 . 
TABLE I.

Average Depths of each Haul (D) in Metres and Numbers of S. elegans (El.) and S. setosa (Se.) in each Catch with the 2-Metre Stramin Ring-trawl, 1926.

\begin{tabular}{rrr}
\multicolumn{3}{c}{ April 9th } \\
$D$. & El. & Se. \\
$S$. & - & 3,075 \\
2 & 266 & 13,044 \\
7 & 1,695 & 17,135 \\
$15 \cdot 5$ & 4,650 & 14,710 \\
$22 \cdot 4$ & 2,137 & 6,083 \\
$32 \cdot 4$ & 1,503 & 3,507
\end{tabular}

\begin{tabular}{rrr}
\multicolumn{3}{c}{ April 13th (i) } \\
$D$. & El. & Se. \\
$S$. & - & 3 \\
$2 \cdot 8$ & 4 & 202 \\
13 & 275 & 2,030 \\
$27 \cdot 6$ & 200 & 570 \\
$35 \cdot 4$ & 102 & 323 \\
41 & 12 & 218
\end{tabular}

\begin{tabular}{rrr}
\multicolumn{3}{c}{ April 13th (ii) } \\
$D$. & El. & Se. \\
$S$. & - & 115 \\
$5 \cdot 8$ & 37 & 888 \\
$13 \cdot 8$ & 116 & 1,334 \\
$21 \cdot 6$ & 304 & 646 \\
$40 \cdot 1$ & 41 & 509
\end{tabular}

\begin{tabular}{rrr}
\multicolumn{3}{c}{ April 22nd } \\
$D$. & El. & Se. \\
$S$. & 1 & 118 \\
5.9 & 3 & 131 \\
$10 \cdot 4$ & 5 & 140 \\
16.9 & 46 & 464 \\
$24 \cdot 6$ & 97 & 363 \\
39 & 61 & 109 \\
41.3 & 44 & 206
\end{tabular}

$\begin{array}{rrr} & \text { April 26th } \\ D . & \text { El. } & \text { Se. } \\ S . & 9 & 40 \\ 3 \cdot 2 & 19 & 51 \\ 12 \cdot 6 & 83 & 167 \\ 16 \cdot 7 & 86 & 124 \\ 20 \cdot 8 & 36 & 24 \\ 37 \cdot 1 & 23 & 19\end{array}$
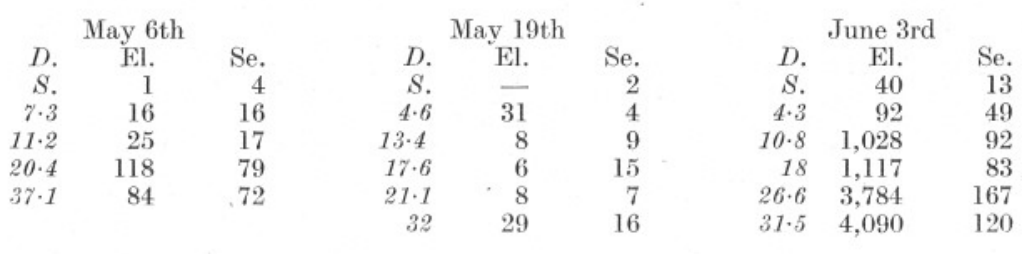

\begin{tabular}{rcr}
\multicolumn{3}{c}{ June 25th } \\
$D$. & El. & Se. \\
$S$. & - & 50 \\
$8 \cdot 2$ & - & 200 \\
$16 \cdot 9$ & 33 & 77 \\
$24 \cdot 6$ & 96 & 144 \\
36 & 54 & 216 \\
$43 \cdot 1$ & 228 & 278
\end{tabular}

\begin{tabular}{rcr}
\multicolumn{3}{c}{ June 30th } \\
$D$. & El. & Se. \\
$S$. & - & 20 \\
$3 \cdot 5$ & 22 & 258 \\
$10 \cdot 4$ & 17 & 20 \\
$21 \cdot 4$ & 326 & 354 \\
$31 \cdot 6$ & 355 & 1,125 \\
$35 \cdot 2$ & 955 & 2,125
\end{tabular}

\begin{tabular}{rcr}
\multicolumn{3}{c}{ July 6th } \\
$D$. & El. & Se. \\
$S$. & - & 350 \\
$3 \cdot 3$ & 76 & 764 \\
$7 \cdot 9$ & 173 & 787 \\
$20 \cdot 9$ & 250 & 530 \\
$24 \cdot 7$ & 265 & 795 \\
$37 \cdot 2$ & 302 & 778
\end{tabular}

\begin{tabular}{rcr}
\multicolumn{3}{c}{ July 13th } \\
$D$. & El. & Se. \\
$S$. & 14 & 666 \\
$2 \cdot 3$ & 166 & 1,904 \\
$11 \cdot 2$ & 385 & 385 \\
$20 \cdot 1$ & 144 & 256 \\
$26 \cdot 4$ & 72 & 288 \\
$40 \cdot 7$ & 52 & 208
\end{tabular}

\begin{tabular}{rrr}
\multicolumn{3}{c}{ July 26th } \\
$D$. & El. & Se. \\
$S$. & - & 100 \\
$3 \cdot 9$ & 22 & 408 \\
$11 \cdot 5$ & 442 & 1,568 \\
$18 \cdot 5$ & 727 & 3,553 \\
$28 \cdot 7$ & 321 & 2,599 \\
$35 \cdot 1$ & 347 & 6,593
\end{tabular}

$\left\{\begin{array}{rrr}\multicolumn{3}{c}{\text { Aug. 4th }} \\ D . & \text { El. } & \text { Se. } \\ S(i) & - & 6,550 \\ S(i i) & - & 5,200 \\ 3 \cdot 5 & 1,618 & 7,902 \\ 9 \cdot 5 & 1,278 & 1,502 \\ 22 \cdot 2 & 1,633 & 1,447 \\ 28 \cdot 2 & 672 & 1,008 \\ 39 \cdot 4 & 970 & 970\end{array}\right.$

\begin{tabular}{rcr}
\multicolumn{3}{c}{ Sept. 22nd } \\
$D$. & El. & Se. \\
$S$. & - & 770 \\
$4 \cdot 4$ & - & 2,460 \\
$9 \cdot 6$ & 34 & 3,326 \\
$23 \cdot 5$ & - & 2,840 \\
$28 \cdot 7$ & 25 & 2,465
\end{tabular}




\section{TABLE II.}

Numbers of Sagitta taken in Half-hour Oblique Hauls of the 2-Metre Stramin Ring-trawl.

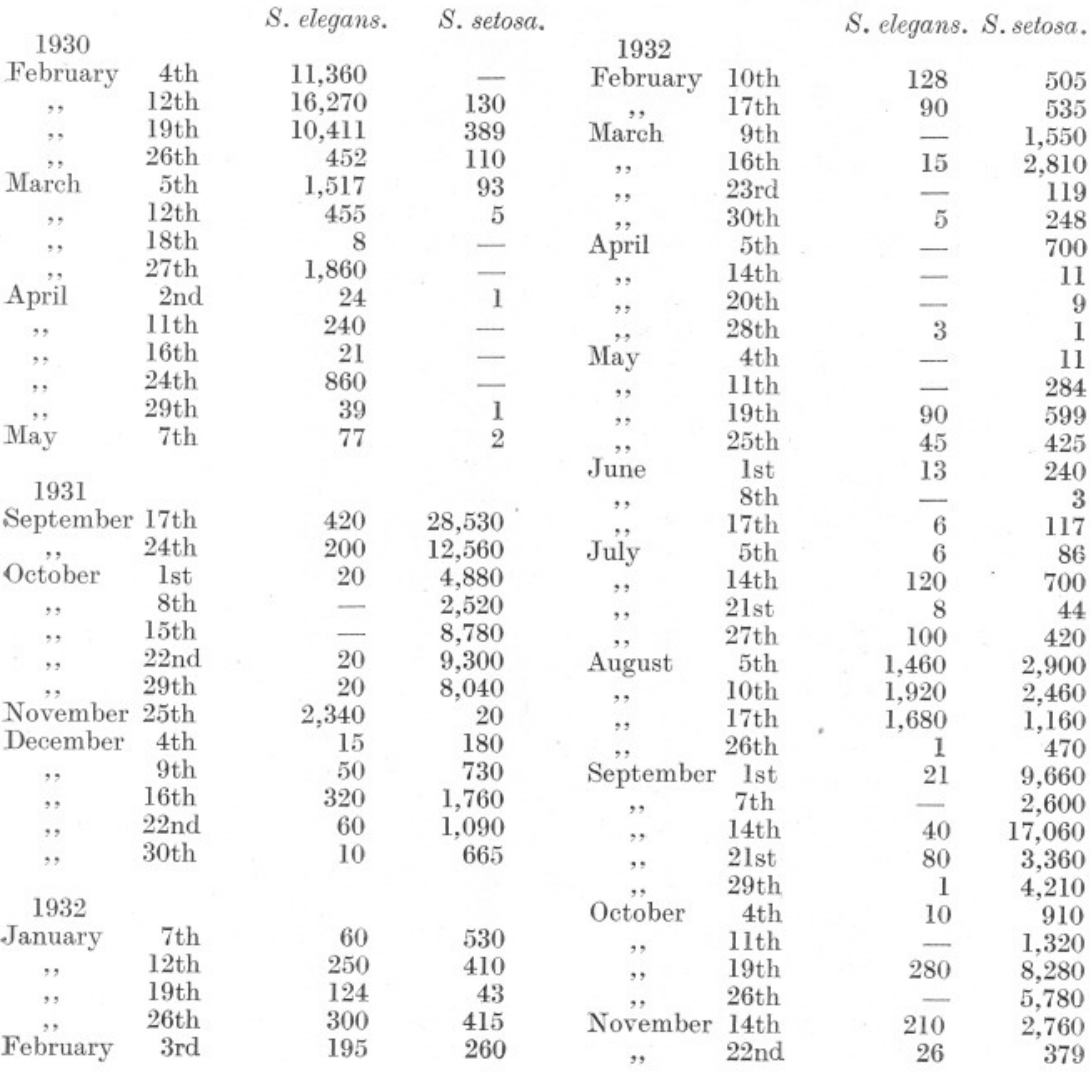




\section{TABLE III.}

Catches of Sagitta in Hauls with Bottom Stramin Net.

\begin{tabular}{|c|c|c|c|c|c|c|}
\hline & $\begin{array}{l}\text { Duration } \\
\text { of Haul. }\end{array}$ & A. & $\begin{array}{l}\text { Rame } \\
\text { Mud. }\end{array}$ & L4. & $\begin{array}{c}\text { Average } \\
\text { per } 30 \mathrm{~min} .\end{array}$ & $\begin{array}{c}A v \cdot \times \\
8 \cdot 5\end{array}$ \\
\hline 2.6 .27 & $10 \mathrm{~min}$. & 11 & 7 & & & \\
\hline ,, & $20 \mathrm{~min}$. & 9 & & & & \\
\hline ," & $30 \mathrm{~min}$. & & 1 & & 18 & 153 \\
\hline &, & & 24 & & & \\
\hline 29.6 .27 & , & 3,535 & $8,330\}$ & & 5,384 & 45,764 \\
\hline - & ,, & 2,010 & $7,660\}$ & & & \\
\hline 8.7 .27 & ", & 225 & $170^{\circ}$ & $175\}$ & 203 & 1,725 \\
\hline 15.7 .27 & $\begin{array}{l}10 \mathrm{~min} . \\
30 \mathrm{~min} .\end{array}$ & 220 & $\begin{array}{l}81 \\
30\end{array}$ & $230^{\circ}$ & 160 & 1,360 \\
\hline 5.8 .27 & , & & & 190 & 190 & 1,615 \\
\hline 12.8 .27 & , , & 4,940 & 365 & 820 & 2,042 & 17,357 \\
\hline 19.8.27 & , & 1,980 & 1,640 & 3,620 & 2,413 & 20,511 \\
\hline 25.8 .27 &, & 630 & 275 & 340 & 415 & 3,528 \\
\hline 31.8 .27 & , & 2,070 & $1,140 *$ & $1,530 *$ & 2,470 & 20,995 \\
\hline 6.9 .27 &, & 1,480 & 1,360 & 1,120 & 1,320 & 11,220 \\
\hline 15.9 .27 & , , & 67 & 80 & 260 & 136 & 1,156 \\
\hline 20.9 .27 &,, & 840 & 730 & 1,881 & 1,150 & 9,775 \\
\hline 30.9 .17 &, , & 40 & 505 & 264 & 270 & 2,295 \\
\hline 4.10 .27 &, , & 185 & 240 & 165 & 197 & 1,585 \\
\hline 13.10 .27 & , & 115 & 810 & 210 & 378 & 3,213 \\
\hline 18.10 .27 &, & 1,170 & 360 & 350 & 627 & 5,330 \\
\hline 25.10 .27 & ,, & 350 & 2,270 & 735 & 1,118 & 9,503 \\
\hline 1.11 .27 &, & 5,180 & 10,720 & 10,780 & 8,893 & 75,591 \\
\hline 6.12 .27 &, , & 1,580 & 1,950 & 2,720 & 2,083 & 17,706 \\
\hline 15.12 .27 &, & 670 & 280 & 1,040 & 663 & 5,616 \\
\hline 21.12 .27 & , & 260 & 840 & 630 & 577 & 4,905 \\
\hline 3.1 .28 &, , & 4,900 & 5,180 & & 5,040 & 42,840 \\
\hline 11.1 .28 & ,, & 1,780 & 1,820 & 4,060 & 2,553 & 21,701 \\
\hline 17.1 .28 &, & 2,980 & 2,580 & 5,880 & 3,813 & 32,411 \\
\hline 26.1 .28 & , & 630 & 580 & 820 & 677 & 5,755 \\
\hline 3.2 .28 &, & 1,130 & 2,280 & 1,540 & 1,650 & 14,025 \\
\hline 10.2 .28 &, & 5,160 & 670 & 630 & 2,153 & 18,301 \\
\hline 14.2 .28 & , & 950 & 80 & 970 & 667 & 5,670 \\
\hline 24.2 .28 &, & 2,160 & 260 & 1,600 & 1,340 & 11,390 \\
\hline 29.2 .28 &, & 670 & 830 & 1,950 & 1,150 & 9,775 \\
\hline 8.3 .28 &, & 790 & 420 & 1,220 & 810 & 6,885 \\
\hline 23.3 .28 &, & 170 & 770 & 420 & 453 & 3,851 \\
\hline 30.3 .28 & , & 6,860 & 1,680 & 390 & 2,977 & 25,305 \\
\hline 12.4 .28 &, & 380 & & & 380 & 3,230 \\
\hline 18.4 .28 & , & 1,490 & 1,960 & 1,090 & 1,513 & 12,861 \\
\hline 23.4 .28 &, & 520 & & & 520 & 4,420 \\
\hline 24.4 .28 &, & & 1,740 & 3,020 & 2,380 & 20,230 \\
\hline 30.4 .28 & , & 640 & 720 & 660 & 673 & 5,721 \\
\hline 11.5 .28 & , & 340 & 180 & 180 & 233 & 1,981 \\
\hline
\end{tabular}

